\title{
FORMATION OF ARTISTIC AND AESTHETIC CULTURE OF STUDENTS IN RURAL SOCIAL ENVIRONMENT
}

\author{
G.V. Artaeva ${ }^{1 *}$, Ya.B. Appaeva ${ }^{2}, I . V$. Kyunkrikova $^{2}$, A.S. Mutyrova ${ }^{1}, I . V$. Shovgurova $^{1}$, and \\ T.M. Boltyrova ${ }^{2}$ \\ ${ }^{1}$ Department of Technology and Management of Professional Education, FSBEU HE the Kalmyk \\ State University named after B.B. Gorodovikov \\ ${ }^{2}$ Department of Pedagogy, FSBEU HE the Kalmyk State University named after B.B. Gorodovikov
}

\begin{abstract}
The article deals with a study of the problem of artistic and aesthetic culture formation in students in rural social environment. Presented in the article are the results of an empirical study that reveals the levels of formation of artistic and aesthetic culture in rural schoolchildren. A hypothesis was tested, that the levels and criteria of artistic and aesthetic culture are associated with factors of the rural social environment, such as life and traditions of their village, as well as natural conditions. Students of two schools, rural and urban, took part in the experiment. Different ages of students were represented in the composition of the experimental and control groups. It has been demonstrated that rural social environment has a positive impact on the development of artistic and aesthetic sense, emotional and sensory perception, appreciative attitude to nature and ancestral cultural heritage, as well as on the development of aesthetic norms and preferences. The results of students' creative work, reflected in decorative and applied activities, are also the indicators of artistic and aesthetic culture formation of students and have a connection with rural society. Artistic and aesthetic culture of students in rural social environment is the result of holistic socio-cultural development.
\end{abstract}

\section{Introduction}

The issue of forming the artistic and aesthetic culture in students is one of the most difficult problems of pedagogical science.

The analysis of pedagogical literature allows us to conclude that the research $[9 ; 10 ; 12]$ was aimed at studying the aesthetic culture of students without considering the artistic component.

Research $[4 ; 6 ; 11 ; 8]$ provides a rationale for a holistic understanding of artistic and aesthetic culture.

Scientists note that artistic and aesthetic culture acts as an integral result of the sociocultural development of an individual and their ability to independent aesthetic and creative

* Corresponding author: lenusya892007@yandex.ru 
activities, which affects the acquisition of valuable personal experience, and, in turn, becomes a reference point in future life of every person $[4,15,16,17,18]$.

It should be noted that to date, the issue related to the influence of the rural social environment on the formation of artistic and aesthetic culture of students has not been studied sufficiently. At the same time, research presented in the pedagogical literature $[2 ; 7$; $13 ; 14]$, reveals the role of the social environment in the educational process of rural schoolchildren.

Nurturing artistic and aesthetic culture of schoolchildren in rural social environment performs the most important social task, which is aimed at the integral development of a person.

As a result of the systematic work on introducing students to artistic and aesthetic activities, they develop valuable spiritual and moral qualities, as well as "...resistance to aesthetically, morally and socially alien and socially dangerous phenomena" [11,4].

Organizing educational activities of schoolchildren, including artistic and aesthetic ones, in rural social environment has its own characteristics due to various objective reasons of social nature.

Organizing artistic and aesthetic activities of primary schoolchildren in rural areas is based on the general principles of education and upbringing, but at the same time it has its own characteristics.

In carrying out educational activities, modern rural schools are guided by generally accepted requirements that reflect solutions of specific tasks and, in curriculum development, take into account the characteristics and conditions of society. To describe the main content of the article, the classification of types of rural schools presented in the scientific and pedagogical literature should be looked at.

Having studied the conditions of rural schools' organization, the scientist L.V. Bayborodova has proposed the following models:

"A school in a district center, where there are cultural and sports institutions, vocational schools, operating enterprises and other schools. There are few of such rural schools, and they have the opportunity to focus on models with a high level of integration processes and connection with environment. Schools of this type are similar in terms of funding and financial opportunities to urban ones and they can choose those models where specialists can be attracted to organize extracurricular activities, additional education, and organize clubs based on these institutions.

A village school where there is an active sports and recreation or cultural center, specialists from these institutions can be attracted and their base can be used. In this and the previous case, a full-time school, a complex school, a club school, and so on can be created.

A small rural school, usually remote from regional and cultural centers. In institutions of this type, there are certain problems associated with the lack of a special base and teachers of additional education. Therefore, there is a need to search for options for organizing extracurricular activities without relying on additional funding and using available resources [3, p. 227-228]."

In this regard, researchers suggest several additional options for organizing extracurricular activities in rural areas, which are already being implemented, and there is some experience of such work.

Currently, not every local community has its own cultural Community Center, so the village school is, first of all, the center of the cultural life of the village, because it is often the only educational institution, the most important factor that influences cultural development of students, and the cultural life of the village as a whole.

Along with the main function of an educational institution to provide a full-fledged subject education, one of the tasks of school is to preserve and spread the culture and historical traditions of the "small" homeland, and to establish itself as a spiritual center of 
rural society. Thus, this contributes to the formation of students' artistic and aesthetic culture in rural social environment.

The analysis of the problem in question allows us to determine the artistic and aesthetic culture of students as a component of the spiritual and material culture of society, which is formed in the course of educational activities. The result of the formation of artistic and aesthetic culture is the presence of artistic and aesthetic perception, artistic and aesthetic sense, aesthetic norms and preferences, as well as appreciative attitude to the ancestral cultural heritage.

The purpose of this study was to identify the levels of artistic and aesthetic culture formation of students in rural social environment.

\section{Methods}

An experimental study aimed at identifying the levels of formation of artistic and aesthetic culture was carried out in the period from September 2018 to May 2019 among students of the Municipal State Institution of Additional Education "Yashalta Children's Art School" (hereinafter - MSI AE "YaCAS") - and MBI "Esto-Altai Secondary School" of the Republic of Kalmykia (age of students 11-15 years) and included three stages of pedagogical experiment.

During the study, we identified two groups: experimental and control. Students who are engaged in MBI "Esto-Altai Secondary School" - Creative Association "Mosaica" (number of students - 25) were an experimental group, and students who attend classes of the Creative Association "Palitra" (for gifted children of the district) (22 students) - a control group.

Students engaged in the Creative Association "Mosaica" attended two-hour classes twice a week, and in the Creative Association "Palitra" - on Saturdays and during school holidays for four-hour classes 2 days.

At the initial stage of our experimental work, the research tasks were defined. They consisted of identifying the level of awareness of students about the types of artistic creativity, the presence of artistic sense, aesthetic norms and preferences, as well as the appreciative attitude to their ancestral cultural heritage.

As a diagnostic tool we have chosen research methods: Test "Beautiful drawing" (L.A. Venger, G. A. Tsukerman), V. Avanesov's questionnaire "Measurement of artistic and aesthetic needs", observation $[5 ; 1 ; 9]$.

Based on the research of B.T. Likhachev [9], we defined the criteria and levels of formation of artistic and aesthetic culture of students.

As a result of theoretical research of the problem of formation of students' artistic and aesthetic culture, we have identified the following criteria: cognitive criterion (formation of knowledge), motivational criterion (stability of interest in decorative and applied activities), performance and activity criterion (presence of practical artistic and aesthetic skills).

The selected criteria allowed us to identify the levels of formation of students artistic and aesthetic culture.

Low level: student has only a general idea about the types of artistic creativity, artistic and creative work (mainly what was included in school training in technology and art classes), does not fully understand the importance of artistic and creative development of a person further in life, answers to questions are brief, not detailed.

Intermediate level: student is familiar with the most common types of artistic creativity, thinks about the fact that artistic knowledge and creative abilities are in demand in life, and are necessary not only for people of creative professions.

High level: creative activities are encouraged within the family, parents or relatives are engaged in any type of creativity, the student has practical experience in one or more types 
of artistic creativity, seeks to develop his artistic knowledge, skills and abilities, and is interested in the little-known types of artistic creativity (studies information on the Internet, in books on creativity).

Analysis of the survey results allowed to conclude that in the control and experimental groups, the level of awareness about the types of artistic creativity and motivation of students to engage in artistic creativity is approximately the same in percentage ratio.

At the same time, it should be noted that students in the Creative Association "Palitra" had higher results, since this group consisted of gifted children who were motivated to engage in creativity.

It has to be noted, that not all children who took part in the experiment showed a wide range of artistic and aesthetic needs and interests, however, they did a good job with the creative task. Therefore, we can conclude that some of the children have natural artistic and creative inclinations.

At the same time, other students who took part in the study have a more conscious interest in artistic creativity, but their natural artistic and creative inclinations are less pronounced, and their drawing skills are also less developed.

Thus, artistic and creative abilities may not exactly coincide with the aspirations and interests of students.

The students who successfully completed the task were considered those who presented a fairly large number of options (4-5). The drawings were distinguished by a non-standard approach to color and composition. In general, the students' works were aesthetic and fitted harmoniously into the storyline of the composition. The students were able to explain and give reasons for their creative ideas and solutions.

The diagnostic study showed that the level of formation of artistic and aesthetic culture of students is at the insufficient level, which confirms the need for purposeful work. Therefore, an additional education program "Mosaica", with an artistic and aesthetic orientation, was developed and tested. The greatest opportunities for the development of artistic and aesthetic culture of rural schoolchildren are provided by educational activities, which are based on a comprehensive exposure of students to decorative and applied activities. The work of the Association is organized based on the implementation of the municipal target program "Gifted Children" in the Yashalta Children's Art School.

\section{Results and discussion}

To describe the results of the study, we shall focus in more detail on the objective conditions under which the experimental work was carried out in rural social environment.

The school in the village of Esto-Altai of the Yashalta district is small, with a total of 86 students (which includes students with disabilities), in the middle grades from 6 to 12 people per class and only in the first grade there are 14 students.

The village of Esto-Altai is not a district center, there are no cinemas, no children's art, music or sports schools, and there is a small Cultural Center where certain cultural and educational work is carried out, but mainly with the older generation (pensioners).

Introduction of students to artistic and aesthetic activities is carried out at technology lessons and classes of the Creative Association "Mosaica", organized at the school for students of $5-8$ grades.

During holidays, the Creative Association "Palitra" for gifted children works for students of Yashalta district schools, where classes are held in the form of field sessions and master classes. This Creative Association is focused on decorative and applied arts.

Each Association has up to 25 students, who consist of different age groups, from 11 to 15 years. The list of associations includes both boys and girls. The complexity of the task 
depends on the age category of children. An individual program with its own calendar and thematic planning has been developed for each Association.

Materials and technical equipment are at a satisfactory level. The study room where classes are held is large, bright, equipped with tables, chairs, a cupboard, and shelves for holding exhibitions. For rural teachers, one of the main problems is the shortage or complete lack of necessary materials and tools for work. In this regard, close contact was made with parents who provided financial support and participated in the educational process.

Thus, the rural social environment has specific features that positively affect the formation of artistic and aesthetic culture of students.

The results of the ascertaining stage of the experiment had the following indicators: in the control group, $18 \%$ of students showed a low level, 55\% - medium level, $27 \%$ - high level, in the experimental group, $28 \%$ of students showed a low level, $56 \%$ - medium level, and $16 \%$ - high level (See Figure 1).

As it was found out at the stage of the ascertaining experiment, children from "Palitra" were at a higher level.

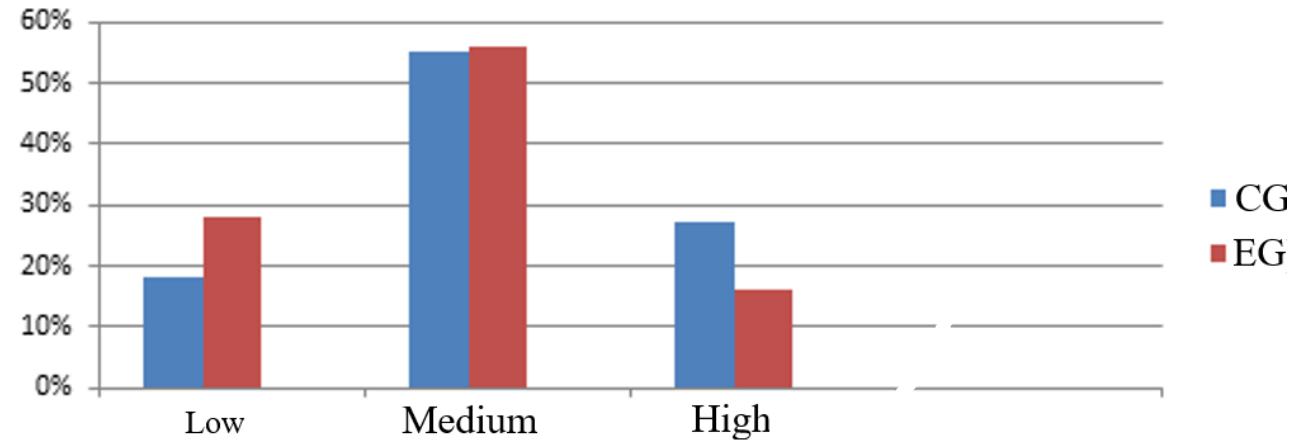

Fig. 1. Results of the ascertaining experiment in two groups.

At the final stage of our experimental work, we carried out repeated diagnostics (control experiment) of students.

Analysis of the results of the study showed that positive dynamics is observed in both groups, but in the experimental group it is slightly more pronounced.

It was also important for our diagnostic work to find out the existing level of creative work of schoolchildren. For this purpose, we have conducted trial lessons on decorative composition. Students were offered several tasks in order to find out the initial level of their practical artistic and aesthetic knowledge and skills.

The first lesson was held outdoors. Students were asked to make several drawings of plants and autumn leaves. Then, in the classroom, children drew variants in a small format of decorative compositions, using their own sketches.

We suggested that students come up with compositions for small sofa pillows (dumkas). Children were explained that they did not need to carefully draw all the details, the main task was to try to come up with a beautiful and harmonious combination of colors (background and plant pattern), and beautifully arrange the image in a square or rectangular format. We also conveyed to the schoolchildren that they could offer a number of options if they wished to.

The following criteria were selected for evaluating artistic and aesthetic works of the schoolchildren:

- number of suggested options;

- harmony of the color scheme; 
- compositional solution (balance, stylization of natural forms);

- originality of the idea;

- level of technical performance of the work (drawing skills, gouache and watercolor skills).

It was also important for us to hear the children's explanations on why they chose certain colors, why they placed the drawing elements one way of another on the sheet plane, and etc. This helped us to understand the students' thought process during the task.

At the final stage, a comparative analysis was carried out. Thus, the comparative analysis of the results of ascertaining and control stages of the experiment showed that in the control group, the low level remained without changes, medium was changed by $9 \%$, and the high level increased by $9 \%$; in the experimental group the low level changed by $12 \%$, medium increased by $4 \%$, the high level increased by $16 \%$, as shown in Table 1 .

Table 1. Comparative analysis of indicators of two groups at the ascertaining and control stages of the study.

\begin{tabular}{|c|c|c|c|c|c|c|}
\hline \multirow{2}{*}{ groups } & \multicolumn{2}{|c|}{ low level } & \multicolumn{2}{c|}{ medium level } & \multicolumn{2}{c|}{ high level } \\
\cline { 2 - 7 } & $\begin{array}{c}\text { ascert. } \\
\text { stage }\end{array}$ & $\begin{array}{c}\text { control } \\
\text { stage }\end{array}$ & $\begin{array}{c}\text { ascert. } \\
\text { stage }\end{array}$ & $\begin{array}{c}\text { control } \\
\text { stage }\end{array}$ & $\begin{array}{c}\text { ascert. } \\
\text { stage }\end{array}$ & $\begin{array}{c}\text { control } \\
\text { stage }\end{array}$ \\
\hline CG & $18 \%$ & $18 \%$ & $55 \%$ & $46 \%$ & $27 \%$ & $36 \%$ \\
\hline EG & $28 \%$ & $16 \%$ & $56 \%$ & $52 \%$ & $16 \%$ & $32 \%$ \\
\hline
\end{tabular}

It should be noted, that the level of growth in the development of artistic and creative abilities was not always proportionally related to the initial level of a particular child, that is, in the learning process, for some students who showed insignificant results, in the end, the dynamics was higher than for those who showed better results at the ascertaining stage.

According to the results of the experimental work, it is worthwhile noting that the children from "Mosaica" not only increased the level of artistic and aesthetic culture, but also demonstrated the presence of artistic sense, aesthetic norms and preferences, as well as an attitude of appreciation of cultural heritage.

In the experimental group, thus, the level of creative performance of works became slightly higher than in the control group, namely:

- more works made based on own sketches, or with significant changes to the composition, color and design solution (independence, originality);

- different techniques and combinations of techniques are used in the performance and decoration of products (combining techniques);

- technical level of performance is also slightly higher;

- composition of the product is more competently organized.

Along with displaying a high level of creative abilities, students demonstrated an appreciative attitude to material household items belonging to the given society.

Thus, it can be concluded that the set of activities carried out in the course of the study, combined with the natural abilities of children, give certain results, taking into account the positive dynamics.

\section{Conclusions}

The results of the empirical study indicate a positive impact of the rural social environment on the formation of artistic and aesthetic culture of students.

It is shown that in the conditions of rural social environment, the formation of artistic and aesthetic culture of students is accomplished with due regard to the everyday life and traditions of their village. 
The source of artistic and aesthetic perception of students is the environment and nature of the village, where independence and originality of solutions are the result of artistic and aesthetic culture.

The results of students' creative works, which are reflected in decorative and applied activities, manifest the artistic and aesthetic sense as a component of artistic and aesthetic culture.

\section{References}

1. Avanesov, V. S. Composition of test tasks. Tutorial book. 3 ed., add. - M.: Testing center, 2002 - $240 \mathrm{p}$.

2. Bayborodova Lyudmila Vasilyevna Extracurricular activities in rural schools: how best to organize it. National Education. 2013. №1. Pp. 227-233

3. Bayborodova, L. V. Education in rural school. L. V. Bayborodova, A. P. Chernyavskaya. - M.: Pedagogical Search, 2002. - 176 p.

4. Butenko, N.V. Artistic and aesthetic culture as a basic mechanism of personal development. Teacher education in Russia.2014. No. 7. - Pp. 138-143.

5. Venger A. L., Zuckerman G.A. Psychological examination of younger schoolchildren. - M: VLADOS-PRESS pub. house, 2005. - 162 p.

6. Gribanova, M.V. Psychological and pedagogical conditions for enriching the artistic and aesthetic competence of preschool children: Educational and methodological guide/ Perm State Pedagogical University - Perm 2003. - 111 p.

7. Gusev, D.A. Trends in the development of rural schools in the context of the fulfillment of pedagogical potential of folk applied art. Scientific Dialogue.2016. No. 4 (52). - Pp. 301-313.

8. Komandyshko E.F., Sedova L.I. Integration of artistic-aesthetic, social and moral experience in the development of spiritual and moral culture of the younger generation [Text]. Artistic and aesthetic development in the context of national and regional education models: Yusov readings. Collection of scientific articles based on the materials of the XVII International Conference "National and regional models of artistic and aesthetic development: Yusov readings" (31.10 - 03.11.2016). Scientific editor E.P. Olesina, ed.-comp. O.I. Radomskaya under the general ed. of L.G. Savenkova. - M.: FSBSU "Institute of Art Education and Cultural Studies of the Russian Academy of Education", 2017. - 481 p.; Pp. 38-45

9. Likhachev, B.T. Theory of aesthetic education of schoolchildren. B.T. Likhachev, M: Prosveshchenie, 1985. - $175 \mathrm{p}$.

10. Mosina, N.V. Aesthetic education of preschool children /Pedagogical skills: materials of the International Scientific Conference (city of Moscow, April 2012). - M: BukiVedi, 2012. - Pp. 119-125.

11. Ostanina, S.A. Pedagogical conditions for the formation of a creative style of artistic and aesthetic activity of schoolchildren in gymnasium educational space. S.A. Ostanina.Young scientist. - 2011. - №4.Vol. 2. - Pp. 110-112.

12. Semenov, D.S. Indicators of formation of aesthetic culture of students. Skill Online [Electronic source]. - 2015. - 1(6). Access mode: http://ripo.unibel.by/index.php?id=1030

13. Novikov, S.N., Surnova, S.N. Socio-pedagogical conditions for the formation of the foundations of artistic and aesthetic culture of rural schoolchildren. Scientific notes of the OSU. Series: Humanitarian and Social Sciences. 2011. No. 1. - Pp. 297-301. 
14. Novikov, S.N. Methodological foundations of aesthetic education of students of rural small schools by means of folk decorative and applied art: Diss. of Doctor of Pedagogical Sciences. S.N. Novikov. city of Orel, 1995. - 349 p.

15. Barbot B., Besancon M., Lubart T. Creative potential in educational settings: Its nature, measure, and nurture // Education. 2015. Vol. 43. № 4. P. 1-11.

16. HacerMutluDanaci / Procedia - Social and Behavioral Sciences 191 ( 2015 ) 190 - 195

17. Plucker J., Callahan C.M. Research on Giftedness and Gifted Education: Status of the Field and Considerations for the Future. Exceptional Children, 2014. Vol. 80(4), pp. 390-406.

18. Problems of development of aesthetic culture at teenagers by means of the Kazakh decorative and applied arts. Opción, vol. 34, no. 85, 2018 